\title{
Impacts of COVID-19 and fiscal stimuli on global emissions and the Paris Agreement
}

\author{
Yuli Shan ${ }^{1}$, Jiamin Ou ${ }^{2,3}$, Daoping Wang ${ }^{4 凶}$, Zhao Zeng ${ }^{5}$, Shaohui Zhang ${ }^{6,7}$, Dabo Guan ${ }^{8,9} \bowtie$ and \\ Klaus Hubacek (1) 1,7凶
}

\begin{abstract}
The global economy is facing a serious recession due to COVID-19, with implications for $\mathrm{CO}_{2}$ emissions. Here, using a global adaptive multiregional input-output model and scenarios of lockdown and fiscal counter measures, we show that global emissions from economic sectors will decrease by 3.9 to $5.6 \%$ in 5 years (2020 to 2024) compared with a no-pandemic baseline scenario (business as usual for economic growth and carbon intensity decline). Global economic interdependency via supply chains means that blocking one country's economic activities causes the emissions of other countries to decrease even without lockdown policies. Supply-chain effects contributed $90.1 \%$ of emissions decline from power production in 2020 but only $13.6 \%$ of transport sector reductions. Simulations of follow-up fiscal stimuli in 41 major countries increase global 5-yr emissions by -6.6 to $23.2 \mathrm{Gt}$ ( -4.7 to $16.4 \%$ ), depending on the strength and structure of incentives. Therefore, smart policy is needed to turn pandemic-related emission declines into firm climate action.
\end{abstract}

ockdown measures designed to contain COVID-19 (for example, social distancing and closing down non-essential local business) have led the global economy into one of its most severe recessions since 1900 (refs. ${ }^{1-3}$ ). For example, China's gross domestic product (GDP) dropped by $6.8 \%$ in the first quarter of 2020 , compared with the same period in the previous year ${ }^{4}$, while the United States and the European Union saw slumped GDPs of $34.3 \%$ and $12.1 \%$, respectively, in the second quarter of 2020 (refs. ${ }^{5,6}$ ).

The pandemic and lockdown policies not only affect production activities and people's lifestyles but also lead to substantial changes in energy consumption and $\mathrm{CO}_{2}$ emissions. For example, global energy demand fell by $3.8 \%$ in the first quarter of 2020 , compared with the previous year ${ }^{7}$, and industrial coal demand dropped by $8 \%$ due to a decrease in electricity needs ${ }^{8}$, even though there was an increase in residential electricity demand ${ }^{9}$. Although there was a lack of official statistics on energy consumption and economic output, several studies have provided a range of estimates on global emission decline. For example, Liu et al. ${ }^{10}$ estimated a decrease of fossil fuel-related emissions by $5.8 \%$ in the first quarter of 2020 . They calculated the emissions inventories of countries on the basis of activity data from power generation (for 29 countries), industry (for 73 countries), road transportation (for 406 cities), aviation and maritime transport and commercial and residential sectors (for 206 countries). Le Quéré et al. ${ }^{3}$ estimated a decline of $17 \%$ (or 17 million tons) in daily emissions for early April 2020 on the basis of the extent of confinement for different countries. The International Energy Agency (IEA) projected a decline of global $\mathrm{CO}_{2}$ emissions by $8 \%$ (or $2.6 \mathrm{Gt}$ ) in 2020 , which led the $\mathrm{CO}_{2}$ emissions level back to 10 years ago .

Countries are seeking fiscal stimuli to restore the economy, mainly to stimulate household consumption and to improve existing (and build new) infrastructure. This may lead to a rebound of emissions in the near future, just like the rapid emission growth after the 2008 global financial crisis ${ }^{11}$. There are already some studies that have discussed the impact of public recovery policies on the economy and emissions. For example, Hepburn et al. ${ }^{12}$ discussed the climate impact of fiscal rescue plans in G20 countries and further proposed five policy items that could achieve economic and climate goals at the same time. Allan et al. ${ }^{13}$ proposed a net-zero emission economic recovery plan for the United Kingdom. Lahcen et al. ${ }^{14}$ applied a computable general equilibrium (CGE) model for 12 sectors (supply side) and 12 products/services (demand side) to assess the stimulus effects of green recovery policies on economy and emissions in Belgium. Similarly Forster et al ${ }^{15}$ found that green stimuli leading to reductions in fossil fuel could avoid additional global warming of $0.3^{\circ} \mathrm{C}$ by 2050 .

However, the impacts of COVID-19 and recovery plans on global emissions is not settled. There may be several waves of the pandemic in the future, which is predicted potentially to last until 2024, and thus prolonged or intermittent social distancing are likely to be continued at least until 2022 (ref. ${ }^{16}$ ). Global supply chains have been seriously affected and the global economy may face a long-term recession even after the pandemic, with profound impacts on associated emissions. Lessons from history show, for example in a study on 15 major pandemics since the fourteenth century, that there are often significant macroeconomic after-effects of pandemics ${ }^{17}$. Accelerated globalization over recent decades has linked producers and consumers across the globe. Even though the Sino-US trade conflict has led to a deceleration of globalization since 2018 (ref. ${ }^{18}$ ) and COVID-19 further impacted global supply chains, the world is still connected via a highly interdependent production system. The economic impacts of COVID-19 and lockdown policies will be amplified via the ripple effects through global supply chains most

'Integrated Research on Energy, Environment and Society (IREES), Energy and Sustainability Research Institute Groningen, University of Groningen, Groningen, the Netherlands. ${ }^{2}$ Department of Sociology, Utrecht University, Utrecht, the Netherlands. ${ }^{3}$ School of International Development, University of East Anglia, Norwich, UK. ${ }^{4}$ School of Urban and Regional Science, Shanghai University of Finance and Economics, Shanghai, China. ${ }^{5} \mathrm{College}$ of Management and Economics, Tianjin University, Tianjin, China. ${ }^{6}$ School of Economics and Management, Beihang University, Beijing, China. ${ }^{7}$ International Institute for Applied Systems Analysis, Laxenburg, Austria. ${ }^{8}$ Department of Earth System Sciences, Tsinghua University, Beijing, China. ${ }^{9}$ The Bartlett School

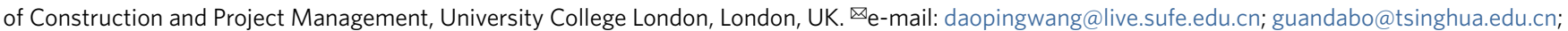
k.hubacek@rug.nl 
Table 1 | Scenarios of lockdown and fiscal stimuli

\begin{tabular}{|c|c|c|c|}
\hline & Dimension & Scenario & Explanation \\
\hline \multirow{9}{*}{$\begin{array}{l}\text { Scenarios of } \\
\text { lockdown }\end{array}$} & \multirow{3}{*}{$\begin{array}{l}\text { Length of lockdown } \\
\text { period }\end{array}$} & $\mathrm{T}$ & Intermittent social distancing scenario from Kissler et al. ${ }^{16}$ \\
\hline & & $\mathrm{T}_{+}$ & $10 \%$ longer time than $T$ \\
\hline & & $\mathrm{T}_{-}$ & $10 \%$ shorter time than $\mathrm{T}$ \\
\hline & \multirow{3}{*}{$\begin{array}{l}\text { Strictness of first } \\
\text { lockdown period }\end{array}$} & S1 & Movements from Google Community Mobility ${ }^{48}$ \\
\hline & & $\mathrm{S} 1_{+}$ & $10 \%$ stronger than S1 \\
\hline & & S1_ & $10 \%$ weaker than S1 \\
\hline & \multirow{3}{*}{$\begin{array}{l}\text { Strictness of future } \\
\text { lockdown period }\end{array}$} & S2 & Strictness of future lockdown periods decreases gradually \\
\hline & & $\mathrm{S} 2_{+}$ & Strictness decreases slower than S2 \\
\hline & & $\mathrm{S} 2$ & Strictness decreases faster than S2 \\
\hline \multirow{8}{*}{$\begin{array}{l}\text { Scenarios of fiscal } \\
\text { stimuli }\end{array}$} & \multirow[t]{2}{*}{ Size of fiscal stimuli } & FS & Ongoing fiscal stimuli introduced before October 2020 \\
\hline & & $\mathrm{FS}_{+}$ & Countries will further increase stimuli to $10 \%$ of their GDP \\
\hline & \multirow[t]{3}{*}{$\begin{array}{l}\text { Structure of fiscal } \\
\text { stimuli }\end{array}$} & $\mathrm{FS}_{\text {current }}$ & $\begin{array}{l}\text { The fiscal stimuli on manufacturing will be allocated to subsectors based on countries' } \\
\text { current economic structure }\end{array}$ \\
\hline & & $\mathrm{FS}_{\text {heavy }}$ & The fiscal stimuli on manufacturing will be allocated to heavy industries \\
\hline & & $\mathrm{FS}_{\text {hightech }}$ & The fiscal stimuli on manufacturing will be allocated to high-tech industries \\
\hline & \multirow[t]{3}{*}{$\begin{array}{l}\text { Sectoral emission } \\
\text { intensity }\end{array}$} & SPS & $\begin{array}{l}\text { Stated policy scenario: emission intensity decreases under the effects of current stated } \\
\text { policies on energy and climate change }\end{array}$ \\
\hline & & SDS & $\begin{array}{l}\text { Sustainable development scenario: emission intensity decreases to achieve the UN } \\
\text { Sustainable Development Goals and the objectives of the Paris Agreement }\end{array}$ \\
\hline & & $\mathrm{CIS}$ & Carbon-intensive scenario: emission intensity remains stable after 2017 \\
\hline
\end{tabular}

likely continuing throughout the coming years. The ripple effects of global supply chains describe "the impact of a disruption propagation on supply chain performance and disruption-based scope of changes in supply chain structural design and planning parameters" ${ }^{\prime 19}$. Recent studies on COVID-19 have found that heterogeneous negative supply shocks induced by control measures can be very costly to aggregate output ${ }^{20-22}$.

Here, we apply a newly developed economic impact model on the basis of global multiregional input-output analysis and the widely used adaptive regional input-output (ARIO) model to estimate the impacts of the COVID-19 crisis and responses on global economy and emissions. Compared with previous studies on socioeconomic impacts of disasters ${ }^{23-25}$, this economic impact model ${ }^{21}$ accounts for direct economic losses from a disaster event and captures industrial/regional indirect impacts of the disaster, which especially refer to the impacts of the epidemic control measures of a certain country or industry on other regions or industries through the ripple effects of the supply chain. In addition, most economic impact assessment models neglect the importance of imbalances between capital availability and labour productivity $^{26-28}$. This model is able to measure available production imbalances by involving labour and capital constraints, set capital recovery as endogenous by considering internal industrial linkages, and assess potential post-disaster economic impacts on the basis of a set of different recovery schemes ${ }^{29-31}$ (Methods).

The impact of COVID-19 on economy and emissions is discussed for the next 5 years (from 2020 to 2024) in 79 countries by defining scenarios of different strictness and duration of lockdown. These countries cover $92.9 \%$ of global GDP in 2018 and $90 \%$ of global emissions in 2017 (see Supplementary Table 1 for notes of countries and sectors). We use the percentage of labour availability and freight capacity ${ }^{32}$ as proxies for strictness of a country's lockdown policies. In addition, we design 18 scenarios in terms of fiscal stimuli to analyse their impacts on the global economy and emissions. We conclude by exploring how COVID-19 and follow-up fiscal stimuli affect the Paris Agreement, and how governments can turn the crisis into an engine for climate action.

\section{Scenarios of global lockdown and effects on $\mathrm{CO}_{2}$ emissions} Countries will impose different lockdown policies at different periods in response to future waves of the pandemic. We therefore set up 27 scenarios with three dimensions: the length of the lockdown period, strictness of the first lockdown period and strictness of future lockdown periods (Table 1 and Methods).

Total emissions from 79 countries are considered, with historical emissions from 1990 to the present and projections under various lockdown scenarios (Fig. 1; detailed country sectoral emissions are provided in Supplementary Table 2). Global emissions decreased temporarily in 2015-2016 due to reduced coal consumption in China $^{33}$ and a faster increase in renewable energy and slower growth in petroleum consumption ${ }^{34,35}$. However, it is premature to say that global emissions reached their peak in 2015 (ref. ${ }^{36}$ ); global emissions increased by $1.1 \%$ in 2017 . According to the prediction by the Greenhouse Gas-Air Pollution Interactions and Synergies (GAINS) model of the International Institute for Applied Systems Analysis $(\text { IIASA) })^{37}$ and IEA World Energy Outlook (WEO) ${ }^{38,39}$, global emissions would keep increasing at an average annual growth of $1.3 \%$ from 2018 to 2024 without the pandemic (grey line in Fig. 1 shows the baseline scenario). The baseline scenario estimates total emissions from 79 countries to be $28.8 \mathrm{Gt}$ in 2020 (1.5\% higher than those in 2019) and a further increase of $1.4 \mathrm{Gt}$ of emissions from 2020 to 2024 (Table 2).

COVID-19 and lockdown policies will potentially cause significant reductions in emissions from 2020 to 2024 (grey area in Fig. 1), ranging from $3.9 \%(5.7 \mathrm{Gt})$ to $5.6 \%$ (8.3 Gt) compared with total emissions under the baseline scenario of $147.7 \mathrm{Gt}$ for the 5 -yr period. In particular, the year 2020 faces the most sudden drop in emissions. Total emissions of 79 countries in 2020 would range from $23.2 \mathrm{Gt}$ (scenario $\mathrm{T}_{+} \mathrm{S} 1_{+} \mathrm{S} 2_{+}$) to $24.3 \mathrm{Gt}$ (scenario $\mathrm{T}_{-} \mathrm{S} 1_{-} \mathrm{S} 22_{-}$) under different scenarios, which are $15.5-19.4 \%$ lower than under the baseline scenario, and would bring the global emissions to the level around 2006 and 2007 (dashed lines in Fig. 1).

Taking scenario TS1S2 as an example (assumed to be the most realistic scenario), the 5 -yr emissions would be $140.9 \mathrm{Gt}$ and $4.5 \%$ 


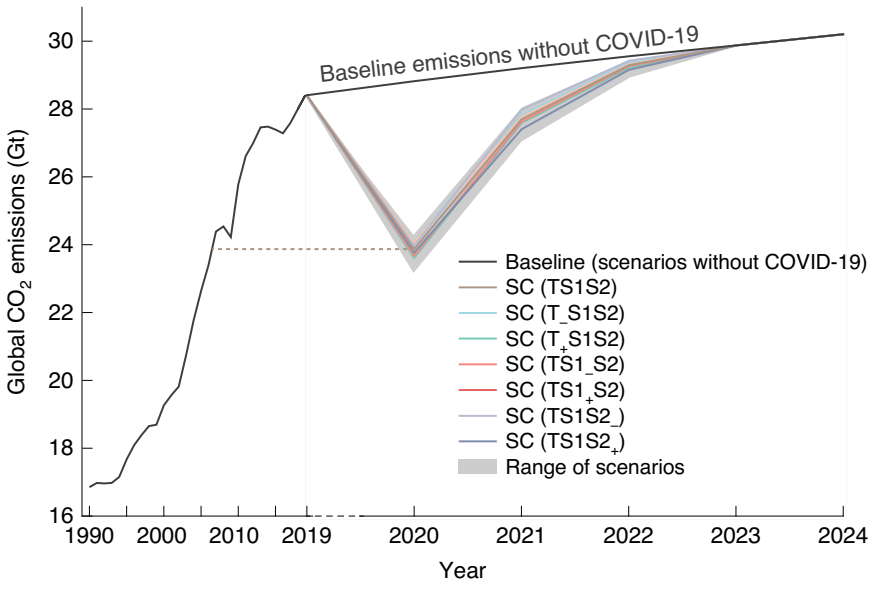

Fig. 1 | Global $\mathrm{CO}_{2}$ emissions (79 countries) under different response scenarios to COVID-19. The grey line shows the baseline emissions without COVID-19. The light grey area shows the range of emissions under 27 lockdown scenarios. Seven key scenarios are drawn in coloured lines to present the effects of change in the length and strictness of lockdown periods. The dashed line shows that COVID-19 brought global emissions in 2020 to the level of around 2006 and 2007.

lower than the baseline scenario. By changing one dimension at the time we can quantify the effects of the three dimensions separately. For example, the green lines in Fig. 1 presents emissions under scenario $\mathrm{T}_{+} \mathrm{S} 1 \mathrm{~S} 2$ (dark green) and scenario T_S1S2 (light green). We find that by adding $10 \%$ to the length of lockdown periods global emissions would decline by $1.10 \%$ in 2020 . In contrast, $10 \%$ shorter lockdown periods would increase global emissions by $0.96 \%$ in 2020. Similarly, increasing the strictness of the first lockdown period by $10 \%$ would decrease emissions by $0.84 \%$ in 2020 . Therefore, the length of lockdown has a greater impact on emissions than strictness. Similar results in terms of economic impacts have also been found by Guan et al. ${ }^{21}$.

\section{Emissions decline by countries and sectors}

Scenario TS1S2 shows that COVID-19 and global lockdown measures would lead to different reductions across countries, with a range of $2.0 \%$ (Cyprus) to $29.3 \%$ (China) in 2020 (shown in Fig. 2a). China is the top country in emission reductions in 2020 with $2.7 \mathrm{Gt}$, accounting for $55.5 \%$ of the overall emission reductions globally. The United States (reduction of $0.49 \mathrm{Gt}, 9.8 \%$ ), the European Union (27 countries) + United Kingdom (0.38, 7.7\%), India (0.30, 6.0\%) and Russia $(0.15,3.1 \%)$ also show substantial declines in 2020 emissions. Such emission reductions are not only caused by the lockdown in the countries themselves (direct impacts) but also affected by the lockdown in other countries (the indirect impacts via global supply chains). For example, in 2020, 76.4\% of emission declines in the United States are caused by lockdown in the country itself and the remaining $23.6 \%$ are caused by the ripple effects of disruptions throughout global supply chains. Also, even though China would not impose any lockdown measures after 2020 in these scenarios, its emissions would still decrease by $0.72 \mathrm{Gt}$ in 2021 , all from indirect emission decline.

The declines in the GDP and emissions of countries differ depending on the structural changes caused by restrictions in labour supply and changes in demand, the roles of countries in global supply chains and carbon intensity of affected sectors, leading to changes in emission intensities (emissions per unit of GDP $)^{40}$ of countries. The global average emission would decline by $4.7 \%$ in 2020 , from 0.35 to 0.33 t per 2015 US $\$ 1,000$ under scenario TS1S2. The declines are mainly caused by changes in industrial structure
Table 2 | Global $\mathrm{CO}_{2}$ emissions (in Gt) under key response scenarios to COVID-19

\begin{tabular}{llllll} 
Scenarios & $\mathbf{2 0 2 0}$ & $\mathbf{2 0 2 1}$ & $\mathbf{2 0 2 2}$ & $\mathbf{2 0 2 3}$ & $\mathbf{2 0 2 4}$ \\
\hline Baseline & 28.82 & 29.20 & 29.56 & 29.88 & 30.21 \\
TS1S2 & 23.87 & 27.70 & 29.29 & 29.88 & 30.21 \\
\hline T_S1S2 & 24.10 & 27.83 & 29.37 & 29.88 & 30.21 \\
T_S1S2 $_{+}$ & 23.61 & 27.59 & 29.21 & 29.88 & 30.21 \\
TS1_S2 & 24.07 & 27.76 & 29.32 & 29.88 & 30.21 \\
TS1_S2 & 23.67 & 27.63 & 29.27 & 29.88 & 30.21 \\
TS1S2_ & 23.97 & 27.98 & 29.43 & 29.88 & 30.21 \\
TS1S2 & 23.77 & 27.40 & 29.16 & 29.88 & 30.21
\end{tabular}

due to lockdown policies. Taking the top five countries in emission decline as an example, China, the United States and the European Union (including the United Kingdom) would see a decline in their emission intensity by $3.9 \%, 1.2 \%$ and $1.9 \%$, respectively. However, India and Russia would see slight increases of $1.5 \%$ and $0.6 \%$, respectively.

In terms of sectors, power and heating production and transport contribute most to emission reduction. Compared with the baseline scenario, these two sectors see emission reductions of $1.9 \mathrm{Gt}(38.7 \%)$ and $1.1 \mathrm{Gt}(22.4 \%)$ in 2020 , respectively, under scenario TS1S2. Decrease in demand for electricity from other sectors accounts for $90.1 \%$ of total emission decline in power production. Meanwhile, the declines in transport-related emissions are caused by two effects. On the one hand, passenger traffic is restricted and people are required to keep social distance. A large share of public transport such as flight, railway and bus, are suspended. Such direct restriction on the transport sectors caused $86.4 \%$ of 2020 emission decline. On the other hand, freight transport also declines substantially due to the restriction of production in factories, which leads to another $13.6 \%$ of indirect emission decline in the transport sectors.

The emissions declines from different sectors vary significantly across countries (Fig. 2c). China, India and Russia would have a high decline in emissions associated with power production, while the United States and the European Union (including the United Kingdom) have higher emission decreases in transport-related emissions. These differences are caused by the existing structure of emissions corresponding to their underlying economic structures. For example, electricity production contributed $52.2 \%$ of China's and $40.7 \%$ of the United States's total emissions in 2017. Thus, the emissions declines in China's electricity production would be higher than those in the United States. However, the sectoral differences across countries are also attributed to the heterogeneity of supply chains in countries. For example, the transport sector accounted for $38.5 \%$ in the United States' scope 1 direct emissions in 2017, contributing $51.3 \%$ of total emission decline over the course of the pandemic. In comparison, China's transport sector accounted for $10.0 \%$ of scope 1 direct emissions in 2017 and contributed $11.1 \%$ of the county's total emission loss during the pandemic. The results imply that the United States's transport sector relies more on global supply chains than China's transport sector. When the pandemic interrupts global supply chains, the US transport sector would face more serious economic loss and associated decline in emissions than would China's transport sector.

\section{Increases in emissions from fiscal counter measures}

Countries are attempting to ameliorate economic shocks through fiscal incentives. The stimuli policies of several major economies have exceeded $10 \%$ of their annual GDP (Supplementary Table 3). As a result, global emissions will receive a boost. The ongoing 
a

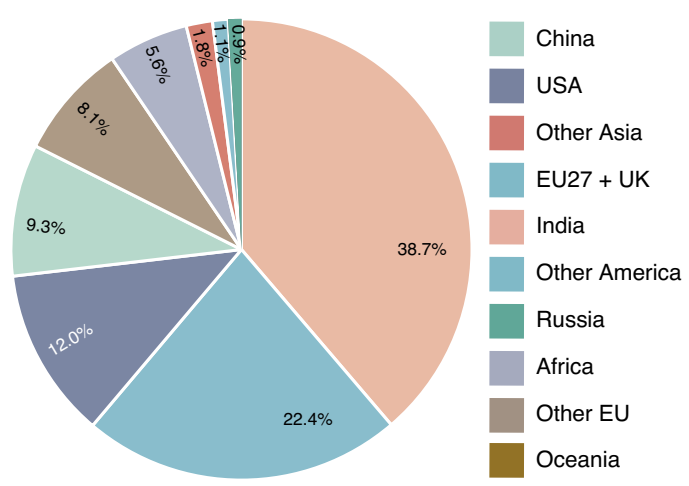

b

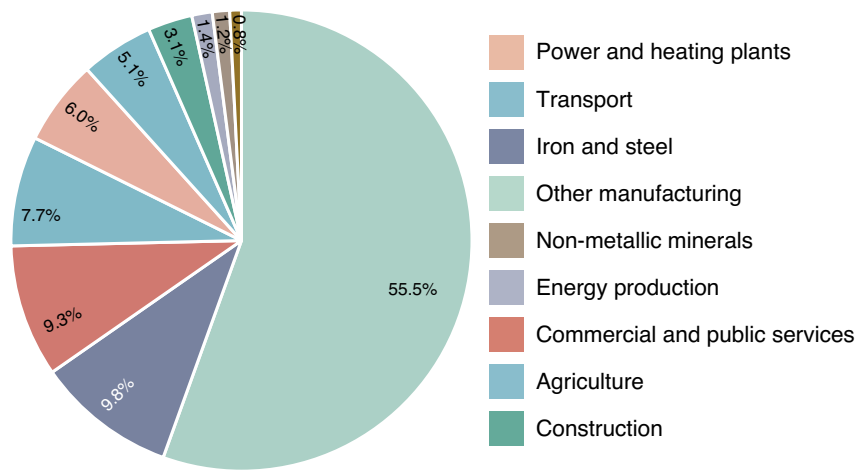

c

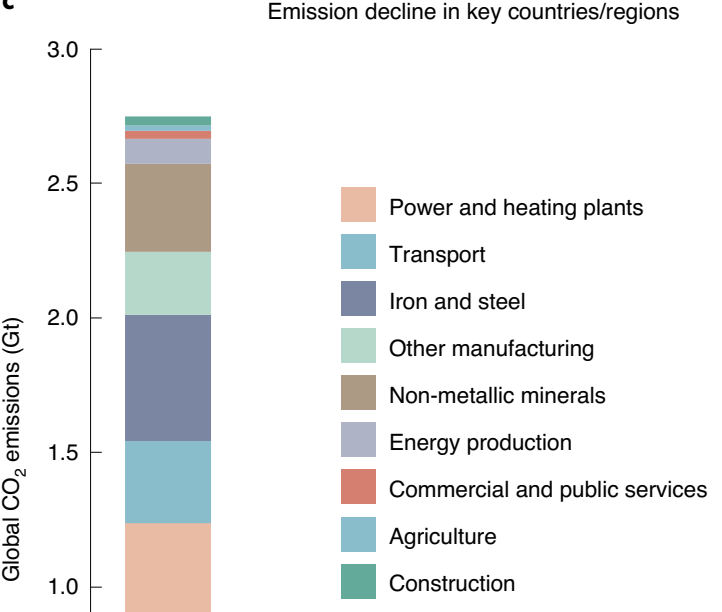

Fig. 2 | Emission decline in 2020 under scenario TS1S2. a, National contribution to the global emission decline. b, Sectoral contribution to the global emission decline. c, Sectoral emission decline in five key countries/regions. The bar charts show the absolute volume of emission decline in nine sectors of the five countries/regions. Pie charts show the structures of emission decline in countries/regions in percentages. EU, European Union; USA, United States of America; EU27 + UK, European Union (27 countries) + United Kingdom.

fiscal incentives and investment will either lead to a replacement of the current fossil fuel-based energy system or aggravate the carbon lock-in effects via investing in traditional infrastructure and capacity and thus reducing future available carbon budget ${ }^{41}$. Therefore, we designed a series of scenarios from three aspects to simulate the impacts of the fiscal stimuli on the economy and emissions: the size of fiscal stimuli, the structure of fiscal stimuli and sectoral emission intensity (Table 1 and Methods).

We use scenario TS1S2 as the baseline of non-incentive scenario (brown line in Fig. 3a). The results show that 5-yr global emissions (2020 to 2024) will range from a reduction of $4.7 \%(6.6 \mathrm{Gt}$, scenario FSFS $_{\text {hightech }}$ SDS) to an increase of $16.4 \%$ (23.2 Gt, scenario $\mathrm{FS}_{+} \mathrm{FS}_{\text {heavy }} \mathrm{CIS}$ ), under different incentive scenarios (full results in Supplementary Table 4).

The 5-yr global GDP and emissions (from 2020 to 2024) will only increase by $0.82 \%$ (or US $\$ 3,466$ billion constant of 2015) and $0.74 \%(1.05 \mathrm{Gt})$ under scenario FSFS $_{\text {current }}$ SPS, which assumes no additional fiscal stimuli will be introduced in the future, the fiscal stimuli to manufacturing will be allocated to subsectors on the basis of the current economic structure of countries and the emission intensity will decrease under the effects of current stated policies on energy and climate change. If countries keep investing fiscal incentives up to $10 \%$ of their 1-yr GDP and keep the current structure, there will be a rebound of global economy and emissions by, respectively, $1.27 \%$ (US $\$ 5,393$ billion constant of 2015$)$ and $1.45 \%(2.04 \mathrm{Gt}$ ) during 2020 to 2024, compared to the non-incentives scenario. We find that one unit of fiscal stimuli in our scenarios will increase global GDP by less than one unit. The main reason is that we only include fiscal stimuli from 41 countries (accounting for $80.9 \%$ of global GDP in 2018), and part of their stimuli will induce additional imports and do not generate value-added of countries that implement the fiscal stimulus. For example, a semiclosed input-output model showed China's 4 trillion yuan stimulus package might have led to an increase in GDP of about 3 trillion yuan ${ }^{42}$.

The changes in the structure of fiscal stimuli will not have significant impacts on economy recovery and emissions. If all current fiscal stimuli on manufacturing are allocated to heavy industries (scenario FSFS $_{\text {heavy }}$ SPS), the global economy would increase by $0.82 \%$ (US $\$ 3,465.7$ billion) and emissions would increase by $0.75 \%$ $(1.07 \mathrm{Gt})$. If the current fiscal stimuli on manufacturing is allocated to high-tech industries (scenario FSFS $_{\text {hightech }}$ SPS), the increase for the global economy and emissions would be $0.82 \%$ (US $\$ 3,466.4$ billion) and $0.75 \%(1.05 \mathrm{Gt})$. In contrast, changes in sectoral emission intensity would have substantial effects on global emissions. If fiscal packages are invested in carbon-intensive technologies and traditional fossil fuel-based infrastructure (scenario CIS or keep the sectoral emission intensity unchanged after 2017), this will bring huge lock-in effects on emissions. Five-year emissions will increase by $15.6 \%(22.0 \mathrm{Gt})$ versus decreases of $4.7 \%(6.6 \mathrm{Gt})$, if the fiscal packages were invested in clean energy and advanced technologies (scenario SDS).

We find that stimuli to household consumption has a higher driving force to economic recovery and emission growth $(28.8 \%$ or $0.30 \mathrm{Gt}$ ) than stimuli to others (Fig. 4a). Household consumption is the major focus of Japan's stimulus package, accounting for $76.3 \%$ of its total budget. Similarly, the United States has a high proportion $(26.3 \%)$ in its stimulus package and this is reflected in the related emission of $78.3 \%$ and $26.0 \%$ of their emission growth, in Japan 

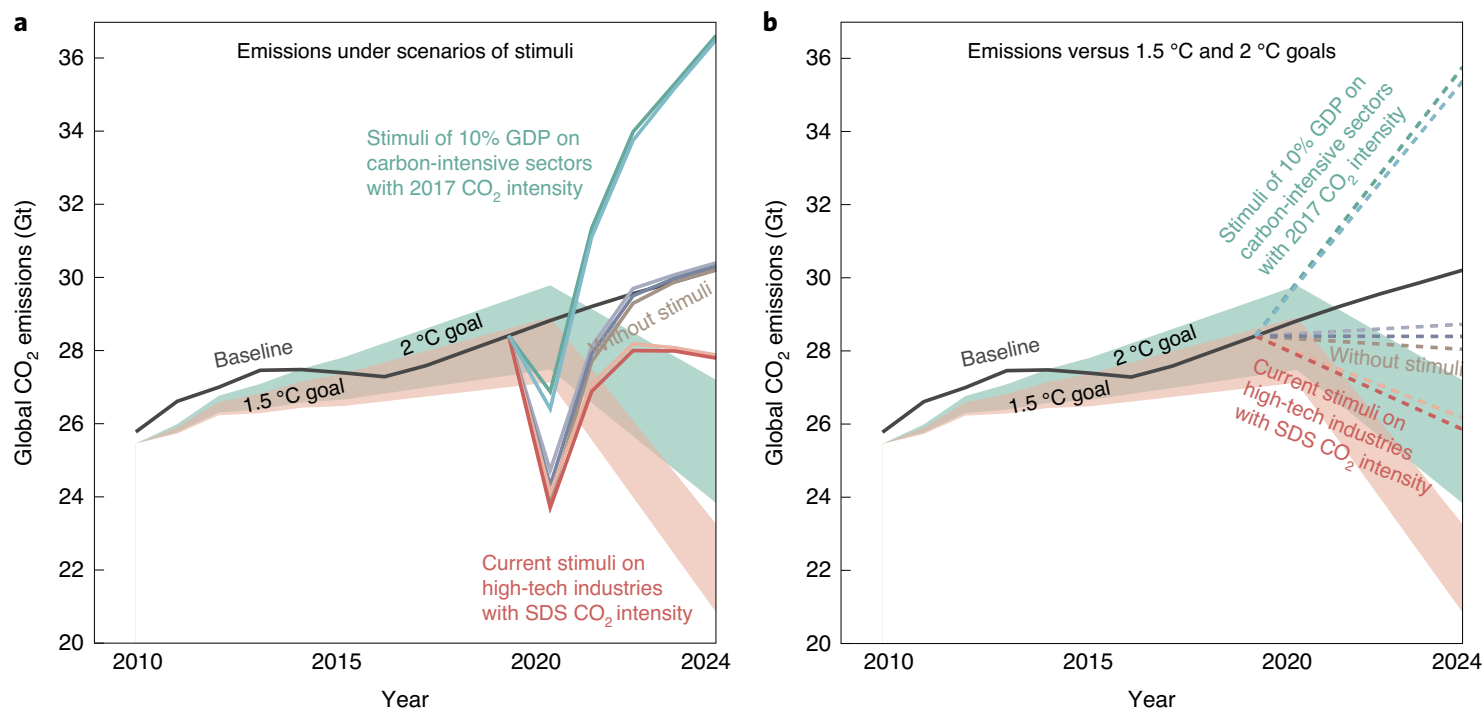

Fig. 3 | Emissions under scenarios of fiscal stimuli and their comparisons with the emission allowance in meeting the $1.5^{\circ} \mathrm{C}$ Paris Agreement goal and $2{ }^{\circ} \mathrm{C}$ Cancun goal (emissions that can be emitted to stay within the climate goals). The emission allowance, shown as green and red areas in the future, are collected from the Climate Action Tracker ${ }^{49}$ and downscaled to accord with the emission levels of 79 countries. $\mathbf{a}$, The emissions under our scenarios. b. The linear emission decline (dashed lines) assuming that the emissions are decreasing uniformly: that is, we allocate total emission losses between 2020 and 2024 evenly to each year.

and United States respectively. Unlike highly industrialized nations, China provides a small stimulus to household consumption (9.5\%). A large part of China's fiscal package (61.9\%) might be invested in infrastructure construction ${ }^{43}$. As a result, the emission increase from stimulating construction accounts for $57.8 \%$ of China's emission growth but stimulating household consumption is only $9.8 \%$. The healthcare sector could be a rising industry in the next generation, as $19.0 \%$ and $10.3 \%$ of China and Germany's stimuli respectively will be invested in the health sectors, including health-related manufacturing and services. The investment on health industries will increase societal well-being and resilience to public health emergencies but will not significantly increase emissions $(0.16 \mathrm{Gt}$ or $15.2 \%$ of the total emission increase globally, Fig. 4a).

Under the most carbon-intensive scenario ( $\mathrm{FS}_{+} \mathrm{FS}_{\text {heavy }} \mathrm{CIS}$ ), global emissions would increase by $16.4 \%$ (23.2 Gt) compared to the non-incentive scenario (Fig. 4c). Current fiscal stimuli will contribute $4.6 \%(1.1 \mathrm{Gt})$ of the emissions increase. Future fiscal stimuli up to $10 \%$ of the GDP of countries will increase global emissions by another $1.0 \mathrm{Gt}$, accounting for $4.3 \%$ of emission increase. High emission intensity will contribute $91.1 \%(21.1 \mathrm{Gt})$ of emissions growth compared to the non-incentive scenario. As for the 'greenest' stimuli scenario ( FSFS $_{\text {hightech }}$ SDS), emissions would decrease by $4.7 \%(6.6 \mathrm{Gt})$ compared with the non-incentive scenario, owing to the decline in sectoral emission intensity (Fig. 4b). Thus, investing in green technologies to reduce sectoral emission intensity is the key to controlling emission growth (or even achieving negative growth) in the post-pandemic era.

\section{The decline in emissions due to COVID-19 and climate targets}

It seems that the decline in emissions due to COVID-19 and lockdown policies could inadvertently help achieve climate change goals; however, it is insufficient for achieving the targets set by the Paris agreement. Comparison of global emissions with climate target emission allowance shows without COVID-19 global emissions (Fig. 3 grey lines) will keep growing and exceed the higher boundary of the $2{ }^{\circ} \mathrm{C}$ Cancun goal in 2021. Considering the effects of COVID-19 (scenario TS1S2, possibly the most realistic scenario according to its settings) and ongoing fiscal stimuli, the dashed line in Fig. 3b) presents the linear emission decline assuming that the emissions are changing uniformly, that is, we allocate total emission changes between 2020 and 2024 evenly to each year. We find that the brown dashed line (scenario without stimuli) can only delay the time when global emissions exceed the upper boundary of the $2{ }^{\circ} \mathrm{C}$ Cancun climate goal.

However, reality could be even worse. First, in this study we only consider the $\mathrm{CO}_{2}$ emissions from economic sectors. Overall emission losses over the period of the pandemic should be less than our estimates, as household emissions from energy use could be slightly increasing due to lockdown policies and people working from home. Second, the emission decline due to COVID-19 might be neutralized by follow-up fiscal stimuli. The world is facing huge risks if such unprecedented amounts of transfers and investment flow into traditional carbon-intensive sectors to rebuild the economy of yesterday. It means not only a short-term increase of emissions but also further lock-in to a fossil fuel-based economy that makes it difficult to change in the future. A latest report by Energy Policy Tacker ${ }^{44}$ shows that around 52\% of the recovery packages in G20 countries would be invested in fossil fuel-related energy sectors, without any environmental commitments attached. Our scenarios show that if fiscal packages target establishing carbon-intensive infrastructure and technologies, global emissions would continue to grow rapidly, even faster than in the previous 5 years. The worst-case option in Fig. 3 (the dark green line) would increase at an average rate of $4.3 \%$ per year and soon exceed the maximum amount of allowed emissions to keep the temperature rise below $2^{\circ} \mathrm{C}$. In contrast, if fiscal packages are invested in high-tech industries with advanced technologies (dark red line in Fig. 3), emissions could potentially be controlled within the emission allowance of the $2^{\circ} \mathrm{C}$ target.

Therefore, severe challenges remain in how to respond to the pandemic but at the same time enormous opportunities exist in restructuring ailing economies requiring financial aid. Countries should take the stimuli plans as a jumpstart to achieve a net-zero energy economy versus further lock-in to carbon-intensive infrastructure, production and consumption patterns ${ }^{41,45}$. However, it is not easy. Despite decades of efforts, dependences of fossil fuels 

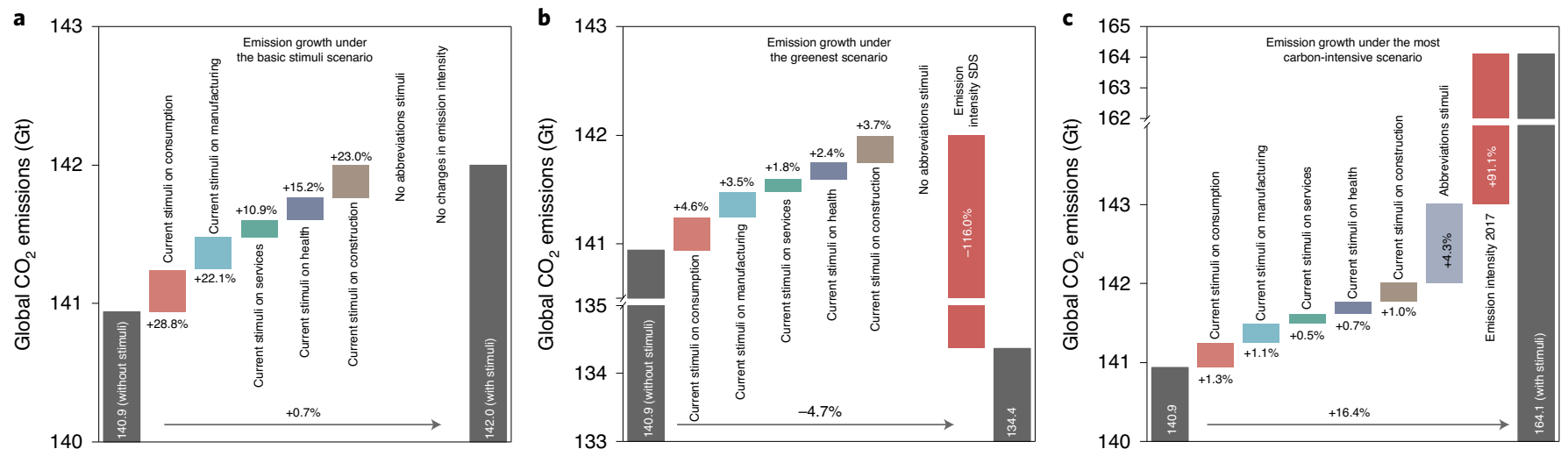

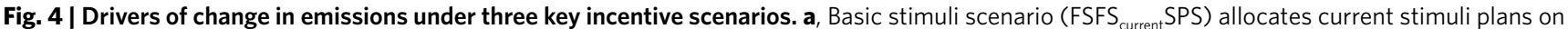
the basis of current industrial structure and emission intensities change with regulations of the stated policies on energy and climate change of countries

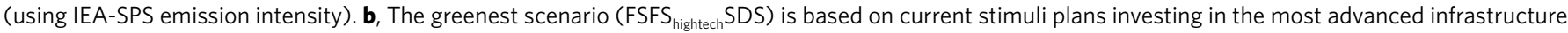
and low-carbon industries. c, The most carbon-intensive scenario $\left(\mathrm{FS}_{+} \mathrm{FS}_{\text {heary }} \mathrm{CIS}\right.$ ) invests up to $10 \%$ of the 1-yr GDP of countries into carbon-intensive sectors with backward technologies. Note the panels have different $y$ axes.

in the energy system remain deep-rooted. As the prices of wind, solar and lithium ion batteries have decreased significantly in the past 10 years, a clean energy system can operate at nearly the same prices as the fossil fuel ones ${ }^{46}$. With a government infrastructure programme to cover the capital costs of clean energy system, the persistent carbon lock-in effect could be broken. Reflecting the governmental fiscal plans after the financial crisis in 2008 when the United Nations Environment Programme proposed the Global Green New Deal, most of them were labelled as failed with a handful of successful cases. Most of the G20 countries failed to deliver the promises. Out of the US $\$ 3$ trillion fiscal stimulus, only $15 \%$ of them were spent on green stimuli during the recession, which accounted for only $0.7 \%$ of G20 GDP ${ }^{47}$. Only China and South Korea invested heavily in environmental stimulus projects with around $3 \%$ of their annual GDP ${ }^{47}$. As a result, the two countries are now better placed in the race for technological superiority of renewable energies than other countries, harnessing increased revenue and employment.

\section{Conclusions}

The lockdown policies in response to the COVID-19 pandemic will lead to substantial changes in energy consumption and $\mathrm{CO}_{2}$ emissions. Total emissions of 79 countries will decrease by 3.9 to $5.6 \%$ in $5 \mathrm{yr}$ (2020 to 2024), compared with a no-pandemic baseline scenario and bring the global emissions 2020 to the level before 2007 .

As countries are designing fiscal stimulus plans to recover the economy, global emissions will increase by $1.05 \mathrm{Gt}$ (0.74\%) during the period of 2020 to 2024, with the ongoing stimuli. Those stimuli could either be a threat to global climate change or a jumpstart to achieve a net-zero energy economy. The large amount of liquidity introduced into the market can either reinforce the carbon lock-in effect by investing in the carbon-intensive sectors or go to clean energy sectors to escape the path dependences of fossil fuel-based production and consumption. The most carbon-intensive scenario would increase 5 -yr global emissions (2020 to 2024 ) by $16.4 \%$ (23.2 Gt). In contrast, the 'greenest' scenario could reduce emissions by $4.7 \%(6.6 \mathrm{Gt})$, if the fiscal stimuli are allocated to high-tech industries with low-carbon technologies. Thus, governments need to be cautious when reopening the economy and designing fiscal stimulus plans.

\section{Online content}

Any methods, additional references, Nature Research reporting summaries, source data, extended data, supplementary information, acknowledgements, peer review information; details of author contributions and competing interests; and statements of data and code availability are available at https://doi.org/10.1038/ s41558-020-00977-5.

Received: 3 July 2020; Accepted: 4 December 2020; Published online: 22 December 2020

\section{References}

1. Hellewell, J. et al. Feasibility of controlling COVID-19 outbreaks by isolation of cases and contacts. Lancet Glob. Health 8, e488-e496 (2020).

2. Anderson, R. M., Heesterbeek, H., Klinkenberg, D. \& Hollingsworth, T. D. How will country-based mitigation measures influence the course of the COVID-19 epidemic? Lancet 395, 931-934 (2020).

3. Le Quéré, C. et al. Temporary deep reduction in daily global $\mathrm{CO}_{2}$ emissions from the COVID-19 confinement. Nat. Clim. Change 10, 647-653 (2020).

4. Preliminary Account of GDP for the First Quarter of 2020 (NBS, 2020); http:// www.stats.gov.cn/tisj/zxfb/202004/t20200417_1739602.html

5. Bureau of Economic Analysis. Gross Domestic Product, Second Quarter 2020 (Advance Estimate) and Annual Update (US Department of Commerce, 2020).

6. GDP and Employment Flash Estimates for the Second Quarter of 2020 (European Commission, 2020).

7. Global Energy Review 2020 (IEA, 2020); https://www.iea.org/reports/ global-energy-review-2020

8. Broom, D. 5 things to know about how coronavirus has hit global energy. World Economic Forum https://www.weforum.org/agenda/2020/05/covid 19-energy-use-drop-crisis/ (2020).

9. Hinson, S. COVID-19 is changing residential electricity demand. Renewable Energy World https://www.renewableenergyworld.com/2020/04/09/ covid-19-is-changing-residential-electricity-demand/ (2020).

10. Liu, Z. et al. Near-real-time monitoring of global $\mathrm{CO}_{2}$ emissions reveals the effects of the COVID-19 pandemic. Nat. Commun. 11, 5172 (2020).

11. Peters, G. P. et al. Rapid growth in $\mathrm{CO}_{2}$ emissions after the 2008-2009 global financial crisis. Nat. Clim. Change 2, 2-4 (2012).

12. Hepburn, C., O'Callaghan, B., Stern, N., Stiglitz, J. \& Zenghelis, D. Will COVID-19 fiscal recovery packages accelerate or retard progress on climate change? Oxf. Rev. Econ. Policy 36, S359-S381 (2020).

13. Allan, J. et al. A net-zero emissions economic recovery from COVID-19. COP26 Universities Network Briefing (Grantham Institute - Climate Change and the Environment, 2020).

14. Lahcen, B. et al. Green recovery policies for the COVID-19 crisis: modelling the Impact on the economy and greenhouse gas emissions. Environ. Resour. Econ. 76, 731-750 (2020).

15. Forster, P. M. et al. Current and future global climate impacts resulting from COVID-19. Nat. Clim. Change 10, 913-919 (2020).

16. Kissler, S. M., Tedijanto, C., Goldstein, E., Grad, Y. H. \& Lipsitch, M. Projecting the transmission dynamics of SARS-CoV-2 through the postpandemic period. Science 368, 860-868 (2020).

17. Jorda, O., Singh, S. R. \& Taylor, A. M. Longer-run Economic Consequences of Pandemics Report No. 0898-2937 (National Bureau of Economic Research, 2020). 
18. Lin, J. et al. Carbon and health implications of trade restrictions. Nat. Commun. 10, 4947 (2019).

19. Dolgui, A., Ivanov, D. \& Sokolov, B. Ripple effect in the supply chain: an analysis and recent literature. Int. J. Prod. Res. 56, 414-430 (2018).

20. Baqaee, D. \& Farhi, E. Nonlinear Production Networks with an Application to the Covid-19 Crisis Report No. 0898-2937 (National Bureau of Economic Research, 2020).

21. Guan, D. et al. Global economic footprint of the COVID-19 pandemic. Nat. Hum. Behav. 4, 577-587 (2020)

22. Mandel, A. \& Veetil, V. The economic cost of COVID lockdowns: an out-of-equilibrium analysis. Econ. Disasters Clim. Change 4, 431-451 (2020).

23. Kajitani, Y. \& Tatano, H. Applicability of a spatial computable general equilibrium model to assess the short-term economic impact of natural disasters. Econ. Syst. Res. 30, 289-312 (2018).

24. Koks, E. E., Bočkarjova, M., de Moel, H. \& Aerts, J. C. Integrated direct and indirect flood risk modeling: development and sensitivity analysis. Risk Anal. 35, 882-900 (2015).

25. Okuyama, Y. \& Santos, J. R. Disaster impact and input-output analysis. Econ. Syst. Res. 26, 1-12 (2014).

26. Koks, E. E. \& Thissen, M. A multiregional impact assessment model for disaster analysis. Econ. Syst. Res. 28, 429-449 (2016).

27. Steenge, A. E. \& Bočkarjova, M. Thinking about imbalances in post-catastrophe economies: an input-output based proposition. Econ. Syst. Res. 19, 205-223 (2007).

28. Hallegatte, S. An adaptive regional input-output model and its application to the assessment of the economic cost of Katrina. Risk Anal. 28, 779-799 (2008).

29. Mendoza-Tinoco, D., Guan, D., Zeng, Z., Xia, Y. \& Serrano, A. Flood footprint of the 2007 floods in the UK: the case of the Yorkshire and The Humber Region. J. Clean. Prod. 168, 655-667 (2017).

30. Mendoza-Tinoco, D. et al. Flood footprint assessment: a multiregional case of 2009 Central European floods. Risk Anal. 40, 1612-1631 (2020).

31. Zeng, Z., Guan, D., Steenge, A. E., Xia, Y. \& Mendoza-Tinoco, D. Flood footprint assessment: a new approach for flood-induced indirect economic impact measurement and post-flood recovery. J. Hydrol. 579, 124204 (2019).

32. Ivanov, D. Predicting the impacts of epidemic outbreaks on global supply chains: a simulation-based analysis on the coronavirus outbreak (COVID-19/ SARS-CoV-2) case. Transp. Res. E 136, 101922 (2020).

33. Zheng, J. et al. The slowdown in China's carbon emissions growth in the new phase of economic development. One Earth 1, 240-253 (2019).
34. Le Quéré, C. et al. Global carbon budget 2015. Earth Syst. Sci. Data 7, 349-396 (2015).

35. Jackson, R. B. et al. Reaching peak emissions. Nat. Clim. Change 6, 7-10 (2016).

36. Quéré, C. L. et al. Global carbon budget 2017. Earth Syst. Sci. Data 10, 405-448 (2018)

37. Greenhouse Gas-Air Pollution Interactions and Synergies (GAINS)_IEA WEO 2019 SPS/SDS Scenarios (International Institute for Applied Systems Analysis, 2019).

38. World Energy Model (IEA, 2019)

39. World Energy Outlook 2019 (IEA, 2019).

40. York, R. Asymmetric effects of economic growth and decline on $\mathrm{CO}_{2}$ emissions. Nat. Clim. Change 2, 762-764 (2012).

41. Tong, D. et al. Committed emissions from existing energy infrastructure jeopardize $1.5^{\circ} \mathrm{C}$ climate target. Nature 572, 373-377 (2019).

42. Chen, Q., Dietzenbacher, E., Los, B. \& Yang, C. Modeling the short-run effect of fiscal stimuli on GDP: a new semi-closed input-output model. Econ. Model. 58, 52-63 (2016).

43. Yao, K. Exclusive: China to ramp up spending to revive economy, could cut growth target - sources. Reuters https://www.reuters.com/article/ us-china-economy-stimulus-exclusive-idUSKBN2161NW (2020).

44. Track Public Money for Energy in Recovery Packages (Energy Policy Tracker, 2020); https://www.energypolicytracker.org/

45. Vergragt, P. J., Markusson, N. \& Karlsson, H. Carbon capture and storage, bio-energy with carbon capture and storage, and the escape from the fossil-fuel lock-in. Glob. Environ. Change 21, 282-292 (2011).

46. Dudley, D. Renewable energy will be consistently cheaper than fossil fuels by 2020, report claims. Forbes https://www.forbes.com/sites/ dominicdudley/2018/01/13/renewable-energy-cost-effective-fossil-fuels2020/\#32197b2c4ff2 (2018).

47. Barbier, E. B. How is the global Green New Deal going. Nature 464, 832-833 (2010).

48. Google Community Mobility Data (Google, 2020); https://www.google.com/ covid19/mobility/

49. 2030 Emissions Gaps (Climate Action Tracker, 2019); https:// climateactiontracker.org/global/cat-emissions-gaps/

Publisher's note Springer Nature remains neutral with regard to jurisdictional claims in published maps and institutional affiliations.

(c) The Author(s), under exclusive licence to Springer Nature Limited 2020 


\section{Methods}

Economic impacts model. A number of well-known modelling methodologies are used to assess economic consequences of COVID-19, such as input-output (IO) analysis and CGE analysis ${ }^{50,51}$. Both IO and CGE are popular for disaster impact assessment with the benefits in their ability to reflect interdependencies of economic sectors. A neoclassical CGE model assumes that the market eventually reaches equilibrium through price adjustments. Such an assumption makes the CGE model usually overestimate the flexibility of the post-disaster market and disequilibrium, especially for sudden disasters ${ }^{52}$. In contrast, our IO-based disaster model explicitly models such disequilibrium shortfalls in supply and demand of different markets reflecting the fact that not all market can adjust flexibly in the short or medium term. Thus, IO-based models are more suitable to capture the impact of sudden shocks on the economy. However, due to a lack of the adaptive behaviour of economic agents in a disaster aftermath, IO-based models may overestimate the impacts of a disaster.

To overcome the rigidity of IO, Hallegatte ${ }^{28}$ developed ARIO. The ARIO model can be used to analyse the disaster-induced influence on regional economy by incorporating the production capacity constraints resulting from capital loss and changes of consumption behaviour within the pre- and post-disaster period, as well as possibilities of over-production ${ }^{53,54}$. Equipped with different datasets of inputoutput linkages, the ARIO model has been used for the impact of COVID-19 in different regions on the local economy. For example, Inoue and Todo ${ }^{55}$ quantified the economic effects of a possible lockdown of Tokyo to prevent spread of COVID19 by applying the ARIO model to the supply chains of nearly 1.6 million firms in Japan. Pichler et al. ${ }^{56}$ used the ARIO model to assess six reopening scenarios of the UK economy to identify an appropriate economic restart strategy.

Here, we extended the ARIO model to a multiregional economic impact model, which has the ability to simulate the propagation of the shocks in multiple regions. After calibrating the model with the latest GTAP database ${ }^{57}$, we assess the dynamic impact of COVID-19 control measures on the global economy throughout production supply chains by considering available production imbalances and consumer behaviour changes ${ }^{21}$.

In our model, there are two types of agents-producers and households. In an economy, each sector can be regarded as a producer, in which labour and capital are the two main inputs for producing products. Meanwhile, economic sectors are also consumers that require intermediate products from other sectors.

There are various estimation methods for industrial production, such as Leontief production function from IO basic theory ${ }^{58}$, Cobb-Douglas function and constant elasticity of substitution (CES) function ${ }^{52}$; in particular, the Leontief production function does not allow for substitution between inputs and is more suitable for this study, as the pandemic occurs without any predication and economic agents cannot make timely adjustments. According to the Leontief function, the output from sector $i$ in region $r\left(x_{i r}\right)$ can be expressed in equation (1).

$$
x_{i, r}=\min \left(\text { for all } p, \frac{z_{i, r}^{p}}{a_{i, r}^{p}} ; \frac{\mathrm{va}_{i, r}}{b_{i, r}}\right)
$$

where $p$ denotes type of intermediate products; $z_{i, r}^{p}$ refers to the intermediate product $p$ used in sector $i ; \mathrm{va}_{i, r}$ refers to the primary inputs for the sector $i$, including labour $(L)$ and capital $(K)$. Values $a_{i, r}^{p}$ and $b_{i, r}$ are the input coefficients of intermediate products $p$ and primary inputs of sector $i$, which can be calculated in equation (2). All the economic transactions and industrial interdependence are expressed as monetary values.

$$
a_{i, r}^{p}=\frac{\bar{z}_{i, r}^{p}}{\bar{x}_{i, r}}, b_{i, r}=\frac{\overline{\mathrm{va}}_{i, r}}{\bar{x}_{i, r}}
$$

It assumes that before the COVID-19 occurred, total output should satisfy intermediate demands and final demands from consumers. However, such economic balances are broken by the pandemic and further crush the supply chains. From the view of producer, restriction of labour input caused by control measures will decrease the production capacity and outputs.

Labour constraints after a disaster may impose severe knock-on effects on the rest of the economy ${ }^{21}$. This makes labour constraints a key factor to consider in disaster impact analysis. For example, in the case of a pandemic, these constraints can arise from employees' inability to work as a result of illness or death, or from the inability to go to work and the requirement to work at home (if possible). In this model, the proportion of surviving productive capacity from the constrained labour productive capacity $\left(x_{i}^{L}\right)$ after a shock is defined as:

$$
x_{i}^{L}(t)=\left(1-\gamma_{i}^{L}(t)\right) \times \bar{x}_{i}
$$

where $\gamma_{i}^{L}(t)$ is the proportion of labour that is unavailable at each time step $t$ during containment. The factor $\left(1-\gamma_{i}^{L}(t)\right)$ contains the available proportion of employment at time $t$.

$$
\gamma_{i}^{L}(t)=\left(\bar{L}_{i}-L_{i}(t)\right) / \bar{L}_{i}
$$

The proportion of the available productive capacity of labour is thus a function of the losses from the sectoral labour forces and its predisaster employment level.
Following the assumption of the fixed proportion of production functions, the productive capacity of labour in each region after a disaster $\left(x_{i}^{L}\right)$ will represent a linear proportion of the available labour capacity at each time step. Take COVID19 as an example: during an outbreak of an infectious disease, authorities often adopt social distancing and other measures to reduce the risk of infection. This imposes an exogenous negative shock on the economic network.

The shortage of intermediate products will further affect the production capacity of downstream sectors and reduce their outputs due to the forward effect. If we consider the limitations of primary and intermediate inputs, the maximum production capacity of sector $i$ in time $t\left(x_{i, r}^{\max }(t)\right)$ can be calculated as equation (5).

$$
x_{i, r}^{\max }(t)=\min \left(x_{i}^{L}(t) ; x_{i}^{K}(t) ; \text { for all } i, r, x_{i, r}^{p}(t)\right)
$$

$x_{i, r}^{L}(t), x_{i, r}^{K}(t), x_{i, r}^{p}(t)$ are the maximum outputs when considering the labour constraints, capital limitation and intermediate input scarcity, respectively.

From the view of demand: (1) direct contact business activities become less when keeping social distancing; and (2) alternative consuming activities impact on the output of producers through changing demand of consumers (backward effect). Hence, the total order demand for the sector $i$ in time $t\left(\mathrm{TD}_{i, r}(t)\right)$ equals to the sum of intermediate demand and household demand (equation (6)).

$$
\mathrm{TD}_{i, r}(t)=\sum_{j, s} \mathrm{FD}_{i, r}^{j, s}(t)+\sum_{s} \operatorname{HD}_{i, r}^{s}(t)
$$

where $\mathrm{FD}_{i, r}^{j, s}(t)$ refers to the order demand that sector $j$ in region $s$ required from supplier $i$ in region $r$ and $\operatorname{HD}_{i, r}^{s}(t)$ is the order demand that household in region $s$ required from supplier $i$ in region $r$.

To make a more realistic representation to the real production process, we assume that each sector holds some inventory of intermediate goods. In each time step, sectors use intermediate products from their inventories for production and purchase intermediate products from their supplying sectors to restore their inventories ${ }^{53}$. The amount of intermediate product $p$ held by sector $j$ in region $s$ in time $t$ is denoted as $S_{j, s}^{p}(t)$ and we assume the inventory of intermediate product $p$ required by sector $j$ in region $s$ is $S_{j, s}^{p,}(t)$, which could fulfil its consumption for $n_{j, s}^{p}$ days.

$$
S_{j, s}^{p, *}(t)=n_{j, s}^{p} \times a_{j, s}^{p} \times x_{j, s}^{\max }(t)
$$

Then the order issued by sector $j$ to its supplying sector $i$ is

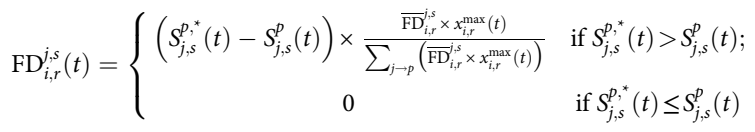

$\operatorname{HD}_{i, r}^{s}(t)$ is measured by the household demand and the supply capacity of their suppliers. In this study, the demand of final products $q$ by household in region $s, \operatorname{HDT}_{s}^{q}(t)$, is given exogenously at each time step. Then, the order issued by household $s$ to its supplier $i$ is

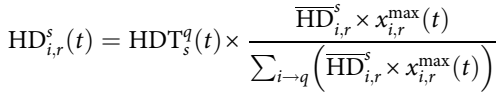

Taking both forward effects and backward effects into consideration simultaneously, the actual output of the producer $i$ in time $t\left(x_{i, r}^{a}(t)\right)$ is

$$
x_{i, r}^{a}(t)=\min \left(x_{i, r}^{\max }(t), \mathrm{TD}_{i, r}(t)\right)
$$

The actual production will be allocated to downstream economic sectors and households according to their orders. If the output is not enough to meet all orders, it will be split according to the order proportion ${ }^{28,59}$.

If we assume the growth rate for each producer $(g)$ remains the same within the entire process, then the actual output of the producer $i$ in time $t$ after adjusting the economic growth $\left(\mathrm{xx}_{i, r}^{a}(t)\right)$ can be calculated in equation (11).

$$
\mathrm{xx}_{i, r}^{a}(t)=\left(1+g_{i, r}\right) \times \mathrm{xx}_{i, r}^{a}(t-1) \times\left(\frac{x_{i, r}^{a}(t)}{x_{i, r}^{a}(t-1)}\right)
$$

The code of economic impact model can be accessed from Wang ${ }^{60}$. The global multiregional input-output (MRIO) table used in the model is compiled using the latest GTAP database (v.10) ${ }^{57}$. GTAP database presents values of intermediate products transaction between 65 sectors, the output of each sector and final consumption of commodities in 141 countries/regions. It also provides global bilateral trade links among the sectors and countries/regions. The growth rates of sectoral GDP $\left(g_{i, r}\right)$ are collected from the IIASA's GAINS model ${ }^{37}$ and IEA ${ }^{38,39}$.

$\mathrm{CO}_{2}$ emission accounts. Previous studies used different economic models to forecast emissions. For example, Kavoosi et al.$^{61}$ forecast global $\mathrm{CO}_{2}$ emissions until 
2030 using Genetic Algorithm on the basis of (non)linear equations and historical energy consumption. Hosseini et al. ${ }^{62}$ predict $\mathrm{CO}_{2}$ emissions for Iran until 2030 with multiple linear regression and multiple polynomial regression models. $\mathrm{Mi}$ et al. ${ }^{63}$ developed an Integrated Model of Economy and Climate on the basis of the input-output model to predict emissions for China until 2035 with constraints of economic growth, energy consumption, employment, industrial structure change and so on. Mercure et al. ${ }^{64}$ designed a simulation-based integrated assessment model that combines a macro-econometric prediction of the global economy, a simulation of technology diffusion, and a carbon cycle and atmospheric circulation model of intermediate complexity.

This study seeks to investigate the short-term (next $5 \mathrm{yr}$ ) changes in emission brought by the sudden shock of COVID-19. We assume that the production efficiency, technology level and economic structures are unlikely to change significantly within such a short time. The relationship between emission and GDP (the emission intensity) will not change much. Therefore, we simply estimate the emissions of countries on the basis of their sectoral emission intensities and economic outputs (shown in equation (12)). A similar method has been used to estimate the recent emission decline in Chinese provinces ${ }^{65}$.

$$
\text { Emissions }_{i r}^{t}=\text { intensity }_{i r}^{t} \times \text { output }_{i r}^{t}
$$

In the equation, subscripts $i$ and $r$ represent sector and country/region, respectively. The superscript $t$ stands for year. Values for output ${ }_{i r}^{t}$ are collected from the above economic impact model. The value intensity ${ }_{i r}^{t}$ refers to per output emissions. The historical emissions are collected from the IEA ${ }^{66}$. The emission intensities are collected from IIASA's GAINS model ${ }^{37}$ and IEA ${ }^{38,39}$ (see Scenarios of fiscal stimuli).

Scenarios of lockdown. We set the scenarios of lockdown from the dimensions of period and strictness. The basic scenario is designed on the basis of the literature and Google Mobility data, and a series of scenarios are designed to reflect the sensitivity of the basic scenarios.

Lockdown periods. Kissler et al. ${ }^{16}$ projected the dynamic spread of the pandemic over the coming years and defined intermittent social distancing scenarios under restriction of critical care capacities. With reference to their results, we define three scenarios for 'lockdown periods' and 'recovery periods'. Basic scenario T is in accord with the intermittent social distancing scenario defined by Kissler et al. ${ }^{16}$, scenario $\mathrm{T}_{+}$has $10 \%$ longer time for each lockdown period, while scenario $T_{-}$has $10 \%$ shorter. See Supplementary Table 5 for detailed lockdown periods for scenarios.

Strictness of the first lockdown period. We define three scenarios for the strictness of the first period. The basic scenarios (S1) are calculated on the basis of Google Community Mobility data ${ }^{48}$. Google provides the daily changes in people's movement trends since 15 February across six types of places: retail and recreation, groceries and pharmacies, parks, transit stations, workplaces and residential area. We use the average of declines in movement trends from workplaces and increase from residential area to reflect the loss of labour availability and freightage capacity in different countries. We exclude the weekends and use the daily average value between 15 March and 31 July as the lockdown strictness for the first lockdown period. For China, we use the mobility data from Baidu and get $80 \%$ as the strictness of its first lockdown period ${ }^{67}$. Supplementary Table 6 shows the basic scenario of the strictness of first lockdown period (S1) in the 79 countries. Then we define scenario $\mathrm{S} 1_{+}$as $10 \%$ stronger than $\mathrm{S} 1$ and scenario $\mathrm{S} 1_{-}$as $10 \%$ weaker.

The control measures may have different effects on the labour supply of different sectors. For example, there are no control measures on the lifeline sectors, such as hospitals and pharmaceutical companies. And sectors that have low exposure levels to the virus, such as education, are less affected by the control measures than commercial services which have higher level of exposure. Therefore, we multiply sectoral multipliers with the general strictness level to get the sector-specific strictness. The sectoral multipliers can be designed to differentiate the impact of the pandemic on each sector and are designed on the basis of three dimensions: the exposure level to the virus, whether it is a lifeline, and the possibility of working from home. Multipliers range from 0 to 1 (see Supplementary Table 7) ${ }^{21}$. If a sector's exposure level to the virus is low, and it is a lifeline sector, and it is easy to work from home, the sector's multiplier will be small, indicating that the sector is less affected by the pandemic and the lockdown measures.

Strictness of future lockdown periods. Considering learning effects and potential herd immunity, countries might achieve the same control effects of the pandemic with weaker strictness in future periods of lockdown. Therefore, we design three scenarios of strictness of lockdown in different periods, see Supplementary Table 8.

In all scenarios, we assume that the household demand remains unchanged except for tourism-related demand (decreased to $10 \%$ during the pandemic). First, labour loss, instead of shortfalls in demand, is the main reason that led to a shortage of supply in various markets. In other words, labour loss dominates the economic loss in our model. Second, governments have taken a series of measures to keep demand stable through direct fiscal transfers.
Generally, there might be 'retaliatory consumption' shortly after a disaster. However, we do not consider such a rapid growth of consumption in our scenarios. First, we did not see obvious retaliatory consumption in the real data. The possible reason is that the impact of COVID-19 on economic and people's lifestyle is huge and will last for a longer time compared with ordinary more localized disasters. People might be more willing to hold savings to prepare for future waves of pandemic and possible unemployment (risk avoidance). Second, the pandemic is still ongoing and the lockdown policies might come in waves for several years, as also expressed in our scenarios, and thus people will not increase consumption in the short term.

Scenarios of fiscal stimuli. Size of the fiscal stimuli. The basic scenarios (FS) reflect the current intensity of fiscal stimuli from countries. We summarize the fiscal incentives that have been introduced by the end of September 2020 in 41 countries (accounting for $80.9 \%$ of global GDP in 2018) ${ }^{68,69}$. These fiscal incentives range from $0.7 \%$ (Mexico) to $21.1 \%$ (Japan) of a country's GDP. Supplementary Table 3 shows the ongoing fiscal stimuli by the countries.

Countries keep increasing their fiscal stimuli plans. Six countries (Japan, Canada, the United States, Brazil, Germany and Australia) have already invested over $10 \%$ of their annual GDP by the end of September 2020. Also, considering that China made an economic stimulus plan of 4 trillion yuan $(12.5 \%$ of the country's GDP in 2008) in response to the 2007 global financial crisis, we design the $\mathrm{FS}_{+}$scenario as countries will further increase fiscal stimuli to $10 \%$ of their annual GDP in the coming months.

Structure of the fiscal stimuli. These fiscal incentives mainly stimulate five components: household consumption, infrastructure construction, health industry and services, other service sectors and manufacturing. Supplementary Table 3 shows the proportion of these five parts in the stimuli plans of countries. However, it is still not clear how the countries will distribute the part of manufacturing into subsectors. Therefore, we designed three scenarios: scenario $\mathrm{FS}_{\text {current }}$ assumes that the stimuli part of manufacturing will be allocated to subsectors on the basis of the current economic structure of countries; scenario $\mathrm{FS}_{\text {heavy }}$ allocates the fiscal stimuli into heavy industries that are usually carbon intensive; scenario $\mathrm{FS}_{\text {hightech }}$ allocates the fiscal stimuli into high-tech industries that are high value-added and low carbon intensive.

Emission intensity. With the ongoing fiscal stimuli, emission intensity of the sectors of countries may change hugely in the coming years. If those fiscal packages are invested in traditional fossil fuel technologies, the emission intensity will increase and vice versa. This study designed the following three scenarios of sectoral emission intensity changing on the basis of IEA WEO scenarios of future energy trends $s^{38,39}$.

IEA WEO Stated policies scenario (SPS). SPS considers the effects of policies and measures that governments around the world have already put in place, together with the effects of announced policies, as expressed in official targets and plans. It means that all the fiscal stimuli will conform to existing and stated policies. The sectoral emission intensity will decrease slowly.

IEA WEO Sustainable development scenario (SDS). According to IEA, SDS designs a low-carbon pathway towards the UN Sustainable Development Goals and the objectives of the Paris Agreement. For example, the fiscal stimuli will be invested in green deals such as renewable energy technologies. The emission intensity decreases rapidly under SDS.

Carbon-intensive scenario (CIS). The emission intensity will keep stable after 2017 under this scenario. This scenario assumes that the ongoing fiscal stimuli ignore established energy and climate change policies and focus on fossil fuel investments.

Limitations and uncertainties. Our study has the following limitations and future work may focus on these aspects to provide a more accurate analysis of emission decline over the pandemic.

First, our economic model does not consider the production mix nor economic structural changes. Both will remain fairly stable within such a short period of time of $5 \mathrm{yr}$ and especially during a recession year (for example, Feng et al. ${ }^{70}$ ). However, the carbon intensity used in this study varies in line with the IEA scenarios. There might be some mismatch in terms of assumptions used in the IEA scenario versus the constant structure assumption used in this paper.

Second, the capital accumulation retreated exogenously in our ARIO-based model. Specifically, we collected the economic projections from the IIASA's GAINS model as the baseline of our model (scenario without pandemic). Capital accumulation is already embedded in the GAINS model as it uses the same set of economic projections as IEA's WEO $2019\left(\right.$ ref. $\left.{ }^{39}\right)$. In this way, our ARIO-based model focuses on the propagation of sudden and intermittent exogenous shocks (for example, COVID-19 lockdowns) in the supply-chain network. Theoretically, it would be better to have a capital matrix, which is frequently part of dynamic IO and endogenizes the investment dynamics. However, it is rarely applied at the global level due to data limitations. However, it is rarely applied at the global level due to data limitations. An interesting alternative approach on dealing with capital in an IO framework is provided by Södersten et al. ${ }^{71}$ and Södersten and Lenzen ${ }^{72}$ 
but we have not attempted to integrate both quite different modelling approaches in this study. Also, the most important and direct impact of COVID-19 is to disrupt people's participation in normal economic activities and domestic and international transportation, thereby causing indirect losses in the supply-chain networks. For research focused on a longer term than this study, we agree that not considering the dynamic process of capital accumulation and investment would underestimate the potential reduction in economic activities as global investment during the crisis is very likely shrinking ${ }^{73}$. Future studies could use other economic models, for example, a CGE-based model, to simulate the long-term economic effects of investment in the post-pandemic era or explicit representations of investment and capital accumulations as in Södersten et al. ${ }^{71}$ and Södersten and Lenzen $^{72}$ or other dynamic IO models.

Third, the emission intensities of sectors are estimated based on the IEA WEO 2019 Stated policies scenario (SPS) with sectoral details provided by GAINS model, which are designed without considering the pandemic. However, the emission intensities during the pandemic may be higher than the normal levels. The main reason is that even if the factories cannot produce due to restrictions, some facilities are still in operation. We cannot quickly shrink capacity with economic decline. Meanwhile, due to the paralysis of the supply chain, part of the production capacities cannot be converted into economic outputs. Thus, our calculation based on economic outputs may overestimate the emission loss during the pandemic.

Fourth, the fiscal stimuli may have complicated but important long-term effects on economic performance. Our scenarios of fiscal stimuli assume that governments will use loans or other financing tools to provide short-term fiscal stimuli in an attempt to recover the economy. Long-term effects such as increasing taxes to balance the public budget, potential inflation, longer term structural changes and change in interest rates are not considered. Although this is acceptable in the short term, any such long-term effects, may affect the economic and emission path in the future. This is beyond the scope of this paper and the chosen modelling approach.

Finally, we consider the emissions from economic sectors only. Emissions from energy use in households that we ignore in this study may slightly increase due to working from home and increased time at home ${ }^{74}$.

\section{Data availability}

All results have been uploaded to China Emission Accounts and Datasets (https:// www.ceads.net/data/covid_19/) for free download.

\section{Code availability}

The simulation code for the economic impact model can be accessed at https:// doi.org/10.5281/zenodo.4290117 (ref. ${ }^{60}$ ). The minimal input for the code is multiregional input-output table. The sample code and test data for the minimal inputs are also provided.

\section{References}

50. Maliszewska, M., Mattoo, A. \& Van Der Mensbrugghe, D. The Potential Impact of COVID-19 on GDP and Trade: A Preliminary Assessment Report No. 1813-9450 (World Bank, 2020).

51. Mandel, A. \& Veetil, V. P. The economic cost of covid lockdowns: an out-of-equilibrium analysis. Econ. Disasters Clim. Change 4, 431-451 (2020).

52. Koks, E. E. et al. Regional disaster impact analysis: comparing input-output and computable general equilibrium models. Nat. Hazards Earth Syst. Sci. 16, 1911-1924 (2016).

53. Hallegatte, S. Modeling the role of inventories and heterogeneity in the assessment of the economic costs of natural disasters. Risk Anal. 34, 152-167 (2014).

54. Inoue, H. \& Todo, Y. Firm-level propagation of shocks through supply-chain networks. Nat. Sustain. 2, 841-847 (2019).

55. Inoue, H. \& Todo, Y. The propagation of the economic impact through supply chains: the case of a mega-city lockdown to contain the spread of Covid-19. Covid Econ. 2, 43-59 (2020).

56. Pichler, A., Pangallo, M., del Rio-Chanona, R. M., Lafond, F. \& Farmer, J. D. Production networks and epidemic spreading: how to restart the UK economy? Preprint at https://arxiv.org/abs/2005.10585 (2020).

57. Aguiar, A., Chepeliev, M., Corong, E. L., McDougall, R. \& van der Mensbrugghe, D. The GTAP data base: Version 10. J. Glob. Econ. Anal. 4, 1-27 (2019).
58. Miller, R. E. \& Blair, P. D. Input-Output Analysis: Foundations and Extensions 2nd edn (Cambridge Univ. Press, 2009).

59. Li, J., Crawfordbrown, D., Syddall, M. \& Guan, D. Modeling imbalanced economic recovery following a natural disaster using input-output analysis. Risk Anal. 33, 1908-1923 (2013).

60. Wang, D. Economic-impact-model: Disaster Footprint Model v.1.0 (Zenodo, 2020).

61. Kavoosi, H., Saidi, M., Kavoosi, M. \& Bohrng, M. Forecast global carbon dioxide emission by use of genetic algorithm (GA). Int. J. Comput. Sci. Issues 9, 418 (2012).

62. Hosseini, S. M., Saifoddin, A., Shirmohammadi, R. \& Aslani, A. Forecasting of $\mathrm{CO}_{2}$ emissions in Iran based on time series and regression analysis. Energy Rep. 5, 619-631 (2019).

63. $\mathrm{Mi}, \mathrm{Z}$. et al. Socioeconomic impact assessment of China's $\mathrm{CO}_{2}$ emissions peak prior to 2030. J. Clean. Prod. 142, 2227-2236 (2017).

64. Mercure, J.-F. et al. Environmental impact assessment for climate change policy with the simulation-based integrated assessment model E3ME-FTT-GENIE. Energy Strategy Rev. 20, 195-208 (2018).

65. Han, P. et al. Assessing the recent impact of COVID-19 on carbon emissions from China using domestic economic data. Sci. Total Environ. 750, 141688 (2020).

66. World $\mathrm{CO}_{2}$ Emissions from Fuel Combustion (IEA, 2020).

67. Daily Inter-City Travel Data https://qianxi.baidu.com/2020/ (Baidu, 2020).

68. Policy Responses to COVID-19 (IMF, 2020); https://www.imf.org/en/Topics/ imf-and-covid19/Policy-Responses-to-COVID-19

69. Duffin, E. Value of COVID-19 Fiscal Stimulus Packages in G20 Countries as of May 2020, as a Share of GDP (Statista, 2020); https://www.statista.com/ statistics/1107572/covid-19-value-g20-stimulus-packages-share-gdp/

70. Feng, K., Davis, S. J., Sun, L. \& Hubacek, K. Drivers of the US $\mathrm{CO}_{2}$ emissions 1997-2013. Nat. Commun. 6, 7714 (2015).

71. Södersten, C.-J. H., Wood, R. \& Hertwich, E. Endogenizing capital in MRIO models: the implications for consumption-based accounting. Environ. Sci. Technol. 52, 13250-13259 (2018).

72. Södersten, C.-J. H. \& Lenzen, M. A supply-use approach to capital endogenization in input-output analysis. Econ. Syst. Res. 32, 451-475 (2020).

73. The Covid-19 Crisis is Causing the Biggest Fall in Global Energy Investment in History (IEA, 2020); https://www.iea.org/news/the-covid-19-crisis-is-causing-t he-biggest-fall-in-global-energy-investment-in-history

74. Cheshmehzangi, A. COVID-19 and household energy implications: what are the main impacts on energy use? Heliyon 6, e05202 (2020).

\section{Acknowledgements}

This work is supported by the National Natural Science Foundation of China (72091514). We also acknowledge support from the National Key R\&D Programme of China (2016YFA0602604), National Natural Science Foundation of China (41921005, 91846301 and 71873059), the Fundamental Research Funds for the central universities (CXJJ2020-301), the UK Natural Environment Research Council (NE/N00714X/1 and NE/ P019900/1), the Economic and Social Research Council (ES/L016028/1) and British Academy (NAFR2180103)

\section{Author contributions}

Y.S., D.G. and K.H. designed the research. Y.S. led the study and drafted the manuscript with efforts from J.O. and K.H. D.W. and Z.Z. worked on the economic impact model. S.Z. provided the energy and economic data from the IEA and IIASA GAINS model.

\section{Competing interests}

The authors declare no competing interests.

\section{Additional information}

Supplementary information is available for this paper at https://doi.org/10.1038/ s41558-020-00977-5.

Correspondence and requests for materials should be addressed to D.W., D.G. or K.H. Peer review information Nature Climate Change thanks Jan Brusselaers and the other, anonymous, reviewer(s) for their contribution to the peer review of this work.

Reprints and permissions information is available at www.nature.com/reprints. 